\title{
A novel role of bone morphogenetic protein 6 (BMP6) in glucose homeostasis
}

\author{
Martina Pauk ${ }^{1} \cdot$ Tatjana Bordukalo-Niksic $^{1}$. Jelena Brkljacic ${ }^{1} \cdot$ Vishwas M. Paralkar $^{2} \cdot$ Amy L. Brault $^{2}$. \\ Ivo Dumic-Cule ${ }^{1} \cdot$ Fran Borovecki $^{3} \cdot$ Lovorka Grgurevic $^{1} \cdot$ Slobodan Vukicevic $^{1}$ (i)
}

Received: 19 October 2018 / Accepted: 24 November 2018 / Published online: 11 December 2018

(c) The Author(s) 2018

\begin{abstract}
Aims Bone morphogenetic proteins (BMPs) are involved in the development and homeostasis of multiple organs and tissues. There has been a significant focus on understanding the role of BMPs in pancreatic $\beta$-cell dysfunction associated with type 2 diabetes (T2D). Our objective was to investigate the relationship between BMP6 and glucose homeostasis.

Methods $O b / o b$ mice were treated with BMP6 for 6 days and analyzed for insulin release, body weight, lipid parameters and glucose tolerance. Quantitative real-time PCR, chromatin immunoprecipitation and glucose output assays were used to assess BMP6 effect on gluconeogenesis in rat hepatoma H4IIE cells. Specificity of BMP6 receptors was characterized by the utilization of various receptor Fc fusion proteins in luciferase reporter gene and glucose output assays in INS1 and H4IIE cells. Results Treatment of $o b / o b$ mice with BMP6 for 6 days resulted in a reduction of circulating glucose and lipid levels, followed by a significantly elevated plasma insulin level in a dose-dependent manner. In addition, BMP6 improved the glucose excursion during an oral glucose tolerance test, lowering the total glycemic response by $21 \%$. In rat H4IIE hepatoma cells, BMP6 inhibited gluconeogenesis and glucose output via downregulation the PepCK expression. Moreover, BMP6 inhibited glucose production regardless of the presence of cAMP, antagonizing its glycogenolytic effect. BMP6 acted on pancreatic and liver cells utilizing Alk3, Alk6 and ActRIIA serine/threonine kinase receptors.

Conclusions Collectively, we demonstrate that BMP6 improves glycaemia in T2D mice and regulates glucose metabolism in hepatocytes representing an exciting prospect for future treatments of diabetes.
\end{abstract}

Keywords Bone morphogenetic protein $6($ BMP6) $\cdot$ Glucose $\cdot$ Insulin $\cdot$ Ob/ob mice $\cdot$ PepCK

\section{Abbreviations \\ BMP Bone morphogenetic protein \\ OGTT Oral glucose tolerance test \\ TGF- $\beta \quad$ Transforming growth factor- $\beta$ \\ ACVR1A Activin A receptor, type I}

Managed by Massimo Porta.

Martina Pauk and Tatjana Bordukalo-Niksic contributed equally to this work.
BMPR Bone morphogenetic protein receptor

ALK Activin receptor-like kinase

ActRIIA Activin receptor type IIA

DMEM Dulbecco's modified eagle medium

ChIP Chromatin immunoprecipitation

AUC Area under the curve

PepCK Phosphoenolpyruvate carboxykinase

cAMP Cyclic adenosine monophosphate

RT-PCR Real-time polymerase chain reaction

T2D Type 2 diabetes

\section{Introduction}

Bone morphogenetic proteins (BMPs) are members of the transforming growth factor- $\beta$ (TGF- $\beta$ ) superfamily $[1,2]$. BMPs signal to the responding cells via hetero-oligomeric complexes of BMP type I (ACVR1A (Alk2), BMPR1A (Alk3), and BMPR1B (Alk6)) and type II (BMPR2,

Slobodan Vukicevic

slobodan.vukicevic@mef.hr

1 Laboratory of Mineralized Tissues, Center for Translational and Clinical Research, School of Medicine, University of Zagreb, Salata 11, Zagreb, Croatia

2 Pfizer Inc, Groton, CT, USA

3 Department for Functional Genomics, Center for Translational and Clinical Research, School of Medicine, University of Zagreb, Salata 2, Zagreb, Croatia 
ActRIIA, and ActRIIB) serine/threonine kinase receptors [3]. Although, BMPs were originally discovered by their ability to induce bone and cartilage formation, they play distinct roles in the development of other organ and tissue systems $[3,4]$.

Several studies have indicated an important role of BMPs in the development of pancreas [5]. However, little is known about a potential role of BMPs in the regulation of glucose homeostasis and insulin resistance. So far, BMP9 has been identified as a hepatic factor that regulates blood glucose via inhibiting hepatic glucose production and lowering glycaemia levels in normal and diabetic mice [6]. Involvement of BMPs in glucose metabolism has also been demonstrated in mice with attenuated BMPR1A signaling in $\beta$-cells, which lead to decreased expression of key genes involved in insulin gene expression, glucose sensing and diabetes due to impaired insulin secretion [7]. In addition, systemic administration of BMP4 to adult mice stimulated insulin secretion [7], while BMP7 stimulated differentiation of pancreatic exocrine tissue into functional islet insulin-producing cells [8] and restored glucose uptake in cells with attenuated insulin signaling [9]. Also, BMP2 and 6 were proposed as new potent insulin sensitizers in adipocytes based on their ability to increase glucose uptake and to regulate genes involved in glucose and fatty acid metabolisms [10]. These results suggested that BMPs have essential roles in pancreas organogenesis and endocrine cell differentiation and are involved in regulating glucose metabolism in liver, pancreas, adipose tissue and muscle. However, there is no evidence of the bioavailability of BMPs and tissue-specific function of BMPs in diabetic animal models.

It has been previously reported that mis-expression of BMP6 leads to agenesis of the pancreas and reduction in the size of the stomach and the spleen, causing fusion of the liver and duodenum [11]. Taken together, there is an emerging need to understand the precise role of BMP6 in the liver and pancreas in maintaining glucose homeostasis. The present study aimed to further explore the beneficial effect of BMP6 on glucose metabolism and insulin secretion utilizing rodent models of T2D.

\section{Materials and methods}

\section{Animals}

Animal care was in compliance with SOPs of Animal facility; the European convention for the protection of vertebrate animals used for experimental and other scientific purposes (ETS 123). All experiments were approved by the Institutional Animal Care Review and Ethics Committee, University of Zagreb, School of Medicine. Eight-weekold male $o b / o b$ mice (Jackson Laboratory) were housed in conventional laboratory conditions with standard GLP diet (Mucedola, Italy) and fresh water ad libitum. Mice were treated with BMP6 for 6 days (once every $48 \mathrm{~h}$; total of 5 BMP6 i.v. injections) at 10,40 and $60 \mu \mathrm{g} / \mathrm{kg}$, while control group received a vehicle (PBS) $(n=8-10$ per group). Following an overnight fast, on day 7, 2-h post-rhBMP6 dose, OGTT was performed and blood glucose levels were monitored at 15, 30, 60 and $120 \mathrm{~min}$. Glucose was measured using an ACCU-CHECK $®$ glucose assay (Roche). At day 6 , 2-h post-rhBMP6 dose, serum insulin levels were measured using Insulin ELISA kit (Mercodia). Total cholesterol and triglyceride were measured by enzymatic methods using kits (Roche) and Cobas 6000 analyzer (Roche).

\section{Recombinant human BMP6}

The manufacturing of rhBMP6 was conducted by Genera Research (Kalinovica, Croatia). Engineered Chinese Hamster Ovary (CHO) cell line was used to produce and purify rhBMP6 from the media using heparin affinity and hydrophobic interaction chromatography, followed by the reversephase HPLC. Protein was lyophilized and stored at $-20{ }^{\circ} \mathrm{C}$ in vials containing $0.5 \mathrm{mg}>99 \%$ pure rhBMP6.

\section{Glucose output assay}

Rat hepatoma H4IIE cells $\left(1 \times 10^{5}\right.$ per well in 96-well plate) were cultured in DMEM with low glucose (Gibco). After $6 \mathrm{~h}$, media was replaced with glucose production media (Gibco), $20 \mathrm{mM}$ sodium lactate and $2 \mathrm{mM}$ sodium pyruvate. After $18 \mathrm{~h}$, treatments were applied in fresh glucose production media. In BMP6 experiments, cells were treated with increasing BMP6 concentrations for $24 \mathrm{~h}$. In cAMP experiments, cells were treated for 12 and $24 \mathrm{~h}$ with $300 \mathrm{ng} /$ mL BMP6 or in combination with $0.5 \mathrm{mM} \mathrm{Bt}_{2} \mathrm{cAMP}$. In siRNA ActRIIA experiments, cells were treated for $24 \mathrm{~h}$ with BMP6 at 1,10 and $100 \mathrm{ng} / \mathrm{mL}$. In Fc experiments, cells were treated for $24 \mathrm{~h}$ with $100 \mathrm{ng} / \mathrm{mL}$ rhBMP6, and rhAlk3 Fc, rhAlk6 Fc and rhActRIIa Fc chimera proteins (R\&D Systems) at $0.1,1,10$ and $50 \mu \mathrm{g} / \mathrm{mL}$. In all experiments, DMEM served as a control. Media were collected at indicated times and assayed using Amplex Red Glucose Assay (Invitrogen).

\section{Chromatin immunoprecipitation}

H4IIE cells were maintained in DMEM (Invitrogen) and harvested untreated or 3 and $7 \mathrm{~h}$ following rhBMP6 (100 ng/mL) application. The standard ChIP protocol was performed as described [12], except of using antibodies against Smad1,2,3,5,8 (Santa Cruz Biotechnology), RNA polymerase II (Santa Cruz Biotechnology) and histone H3 acetylated at lysines 9 and 14 (Diagenode). The original 
immunoprecipitated and total input DNA aliquots were used to assess the quality of the ChIP. The Smad occupancy was detected by qPCR on a Roche LightCycler at the insulin and $P e p C K$ promoters. The quality of the ChIP was calculated as fold enrichment over myoglobin exon 2 non-binding control region.

\section{Gene expression analysis}

After treatment of H4IIE cells with $100 \mathrm{ng} / \mathrm{mL}$ BMP6 for $12 \mathrm{~h}$, one-step quantitative RT-PCR was performed on $1 \mu \mathrm{g}$ of total RNA using superscript first-strand synthesis system (Invitrogen) with random hexamer primers according to the manufacturer's protocol. Gene expressions were measured using LightCycler FastStart DNA Master SYBR Green kit (Roche) in the LightCycler instrument (Roche) as described [13]. Results were represented as fold change of comparative vehicle expression level, following normalization to hypoxanthine phosphoribosyltransferase 1 (HPRT1).

\section{Luciferase reporter gene assay in INS1 cells}

INS1 cells $\left(2.5 \times 10^{4}\right.$ per well in 48 -well plate $)$ were transfected with a reporter plasmid consisting of BRE from the Id-1 promoter fused to a luciferase reporter gene. After $24 \mathrm{~h}$, the medium was changed to serum-free DMEM/F-12 for $7 \mathrm{~h}$. Cells were then treated for $17 \mathrm{~h}$ with serum-free DMEM/F-12 (Control), rhBMP6 (20 ng/mL) and increasing concentrations of Alk3 and Alk6 chimera proteins, and luciferase activity was measured using the Promega luciferase assay reagent.

\section{Gene knockdown of ActRIIA in H4IIE cells}

H4IIE cells $\left(2 \times 10^{6}\right.$ per $10-\mathrm{cm}^{2}$ dish $)$ were transfected with ActRIIa siRNA (Thermo Scientific). In brief, $6 \mathrm{~mL}$ of OptiMEM media (Gibco) containing $6 \mu \mathrm{L}$ of DharmaFect 1 transfection reagent (Thermo Scientific) and $100 \mathrm{nM}$ of siRNA was added to the dish and incubated overnight. The following day, the transfection media was removed and replaced with fresh growth media. After $24 \mathrm{~h}$, the cells were trypsinized and plated in a 96-well plate and a glucose output assay was performed.

\section{Data analyses}

The data were expressed as mean \pm standard error of mean (SEM) or standard deviation (STDEV). Changes in gene expression and serum parameters were evaluated using the two-tailed Student $t$ test. The results were considered significant when $p<0.05$.

\section{Results}

\section{BMP6 improves glucose tolerance in ob/ob mice}

We tested the ability of BMP6 treatment to influence the plasma glucose levels in $o b / o b$ mouse model. First, we assessed the ability of lower BMP6 doses (10 and $40 \mu \mathrm{g}$ / $\mathrm{kg}$; every $48 \mathrm{~h}$ ) following 6 days of therapy on maintaining glucose levels. BMP6 at $40 \mu \mathrm{g} / \mathrm{kg}$ was efficient in significantly lowering fed plasma glucose from second day onward (Fig. 1a). Importantly, plasma insulin levels measured at day 6 of BMP6 treatment were significantly elevated relative to control in a dose-response manner (Fig. 1b). We did not observe any change in body weight upon BMP6 administration through therapy (Fig. 1c). Treatment with BMP6 at $60 \mu \mathrm{g} / \mathrm{kg}$ following 6 days demonstrated hypoglycemic effect by decreasing plasma glucose at $236.2 \mathrm{mg} / \mathrm{dL}$ compared to $307.3 \mathrm{mg} /$ $\mathrm{dL}$ of the control. On day 7, 2-h post-dose, OGTT was performed, and BMP6 significantly lowered plasma glucose levels and improved glucose tolerance compared to control (Fig. 1d). Total glycemic response was $21 \%$ lower following BMP6 treatment (area under the curve (AUC), $p=0.0128$ ) (Fig. 1e). Since increased plasma levels of triglyceride and cholesterol are frequently associated with insulin resistance, we wanted to determine their levels following 6 days of BMP6 treatment. While BMP6 had no effect on cholesterol, plasma triglycerides levels were significantly decreased (Fig. 1f). Altogether, these results indicate BMP6 effect on maintaining plasma glucose via affecting the insulin release in $o b / o b$ mice.

\section{BMP6 regulates glucose homeostasis via regulation of hepatic glucose output}

To understand the mechanism of BMP6 action, we studied its effect in H4IIE rat hepatoma cell line. BMP6 treatment significantly downregulated PepCK expression (95\%) with very little change in the expression of other metabolic enzymes at 12-h treatment (Fig. 2a). To ascertain possible alterations in promoter recruitment of genes related to the insulin pathway, chromatin immunoprecipitation (ChIP) experiments on H4IIE cells were performed. Using the ChIP-grade antibody against Smad 1,2,3,5 and 8, we observed an increased PepCK promoter recruitment $7 \mathrm{~h}$ following BMP6 treatment (Fig. 2b). The same was not observed with specific primers for the insulin promoter. To ensure that potential observed binding events are the result of an active transcription, we performed ChIP experiments using antibodies specific for RNA Polymerase II and histone $\mathrm{H} 3$ acetylated at lysine 9 and 14 . We showed a marked 
a

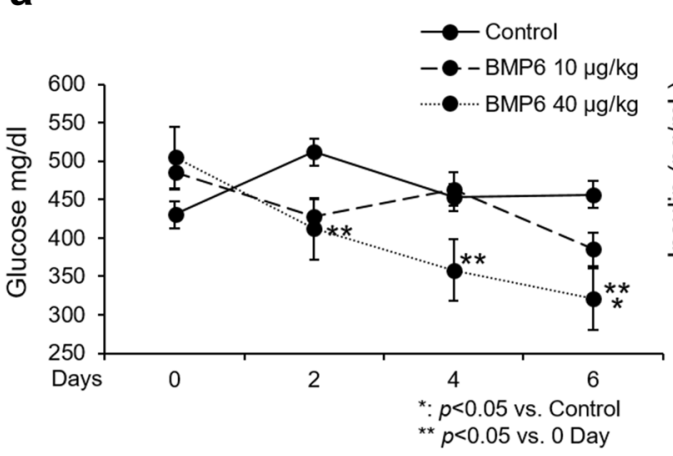

b

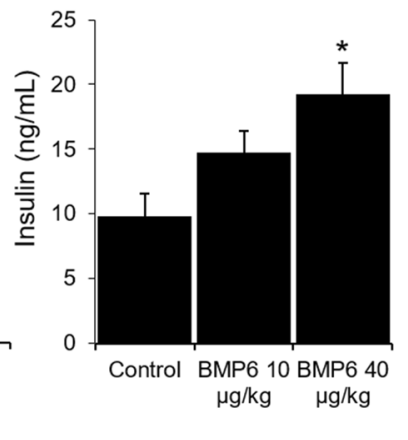

C

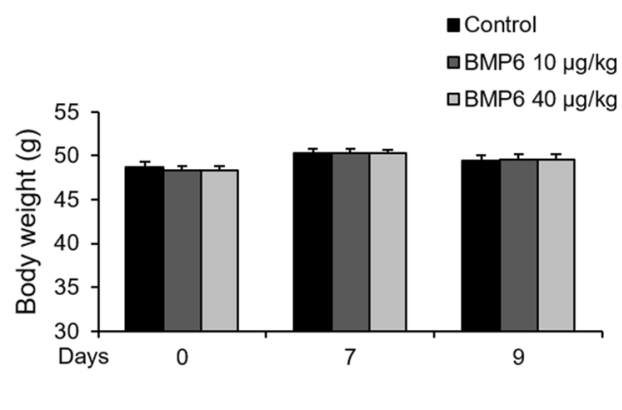

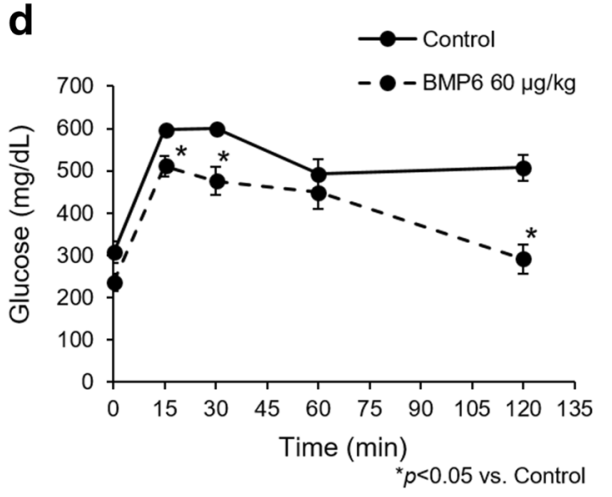

Fig. 1 BMP6 is a hypoglycemic agent in ob/ob mice. Following BMP6 therapy (10 and $40 \mu \mathrm{g} / \mathrm{kg}$; every $48 \mathrm{~h}$ for 6 days) in 8-week-old $o b / o b$ mice $(n=8-10)$, we measured at 2 -h post-dose a fed plasma glucose every other day, $\mathbf{b}$ circulating insulin levels at day 6 , and $\mathbf{c}$ body weights during 9 days of treatment. Oral glucose tolerance test (OGTT) was performed on day 7, 2-h post-BMP6 $(60 \mu \mathrm{g} / \mathrm{kg})$ treat- ment and $\mathbf{d}$ glucose was measured at $0,15,30,60$ and $120 \mathrm{~min}$ and e AUC was calculated. Upon BMP6 $(60 \mu \mathrm{g} / \mathrm{kg})$ treatment for 6 days, f circulating cholesterol and triglycerides levels were measured. Results are reported as the mean \pm SEM. ${ }^{*} p<0.05$ vs. control, $* * p<0.05$ vs. 0 day decrease in PepCK promoter recruitment by acetylated $\mathrm{H} 3$ histones following BMP6 administration (Fig. 2b), while no recruitment of the insulin promoter was observed. The RNA polymerase II binding to the insulin and PepCK promoters was not detected. These results point to the possible negative regulation of PepCK transcriptional activity by BMP6. Next, we analyzed BMP6 effect on glucose output in H4IIE cells and showed that BMP6 significantly inhibited hepatic glucose output in a dose-response manner with an IC-50 of $174 \mathrm{pM}$ (Fig. 2c). As one of the key enzymes in hepatic gluconeogenesis, PepCK is regulated mainly by glucagon and insulin that stimulate and repress its gene transcription, respectively. Since glucagon stimulation on PepCK is exerted via cyclic adenosine monophosphate (cAMP), we tested whether BMP6 may act to antagonize its glycogenolytic effect. BMP6 significantly decreased the glucose output 12 and $24 \mathrm{~h}$ following treatment, while cAMP addition was followed by a higher glucose output (Fig. 2d, e). Inhibitory effect of BMP6 on glucose output was sustained even after stimulation with cAMP. Overall, BMP6 directly decreased the hepatic glucose production through downregulation of the PepCK expression regardless of the presence of cAMP.

\section{Characterization of BMP6 receptors in mediating glucose output}

The specificity of BMP6 actions in vitro was further characterized by the utilization of various receptor Fc fusion proteins. These studies identified that Alk3 and Alk6 (BMPR1A and 1B) were able to inhibit BMP6-stimulated luciferase activity of a BRE promoter construct in INS1 cells (Fig. 3a, b). In H4IIE, Alk3 and Alk6 Fc fusions partially inhibited BMP6 effects on the glucose output, whereas ActRIIA Fc fusion was partially able to rescue the inhibition of glucose output by BMP6 (Fig. 3c, d, e). Knockdown of the ActRIIA gene expression reversed the inhibition of glucose output by BMP6 indicating that in hepatocytes ActRIIA plays a major role in transducing BMP6 activity (Fig. 3f). Together, these data indicate that BMP6 has a direct specific action on pancreatic cells and hepatocytes, and utilizes Alk3, Alk6 and 
a

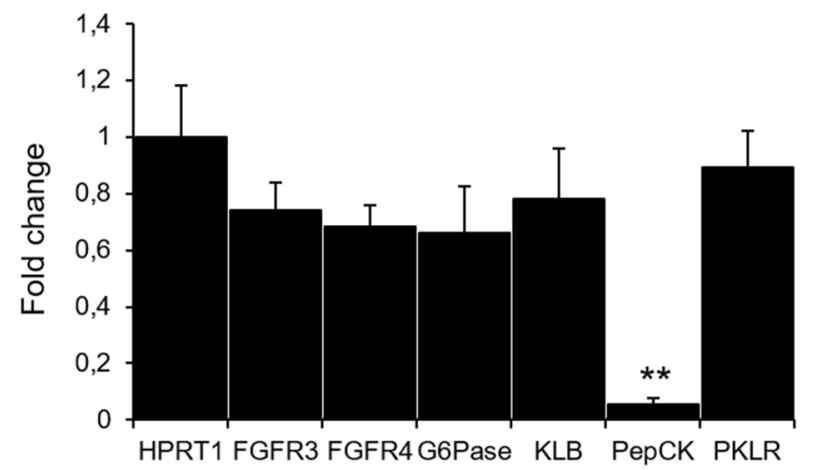

b

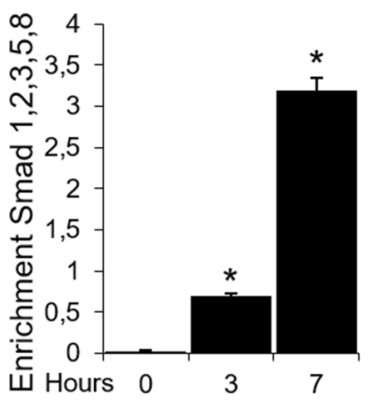

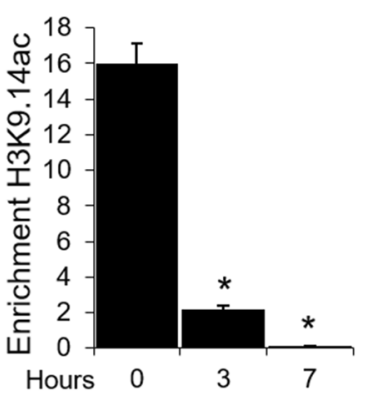

C

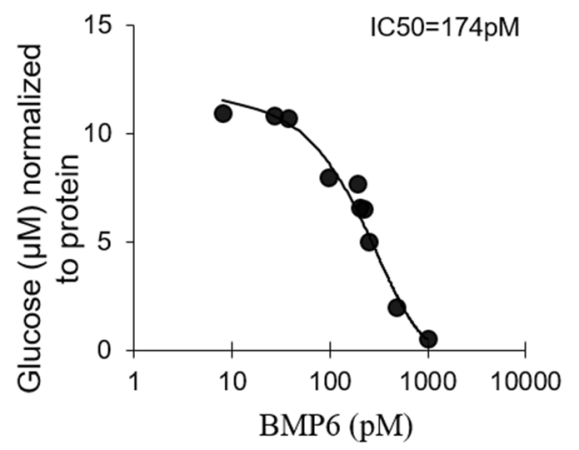

d

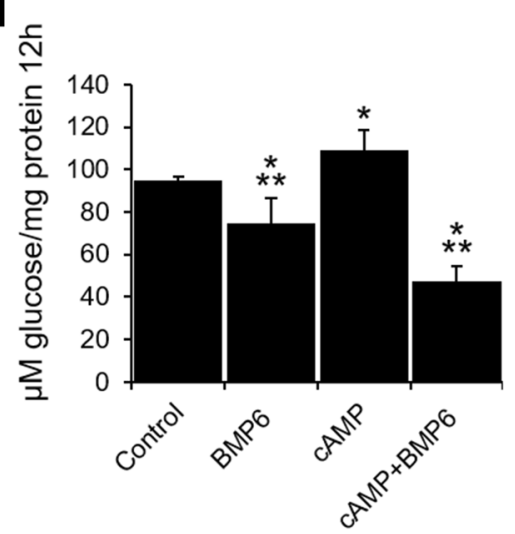

e

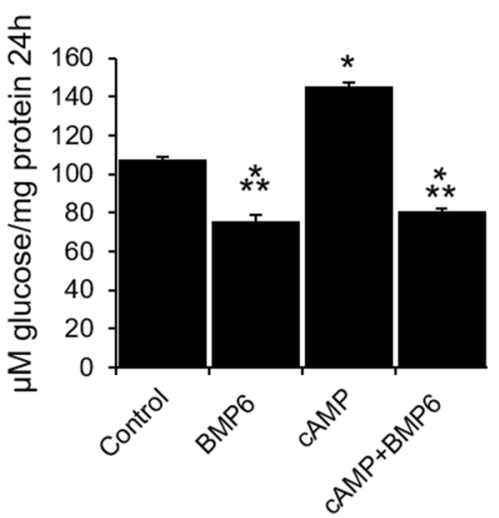

Fig. 2 Role of BMP6 in hepatic gluconeogenesis. Following BMP6 $(100 \mathrm{ng} / \mathrm{mL})$ treatment in H4IIE cells $(n=4)$ at $12 \mathrm{~h}$, we measured a gene expression by qRT-PCR of fibroblast growth factor 3 (FGF3), fibroblast growth factor receptor 4 (FGFR4), glucose-6-phosphatase (G6Pase), betaKlotho (KLB), phosphoenolpyruvate carboxykinase (PepCK) and pyruvate kinase L/R (PKLR) and hypoxanthine phosphoribosyltransferase 1 (HPRT1). Results are represented as fold change of vehicle expression level, following normalization to

ActRIIA to initialize signaling events that ultimately result in gene transcription regulation.

\section{Discussion}

There has been a significant focus on understanding the involvement of BMPs in $\beta$-cell dysfunction associated with $\mathrm{T} 2 \mathrm{D}$, but there are many conflicting results regarding the effect of BMPs on glucose homeostasis and pancreatic cell function. Here, we tested whether BMP6 has beneficial effect on glucose homeostasis and insulin secretion using T2D mice model. In $o b / o b$ mice, BMP6 was effective in lowering plasma glucose levels during 6 days of therapy, but more importantly, it improved glucose excursion during an OGTT. Also, BMP6 significantly elevated serum insulin levels in a dose-response manner. Previously, BMP9 was shown to be effective in lowering plasma glucose at a high
HPRT1. b PepCK promoter recruitment was assessed 3 and $7 \mathrm{~h}$ following BMP6 $(100 \mathrm{ng} / \mathrm{mL})$ treatment by chromatin immunoprecipitation using antibodies against Smad1,2,3,5 and 8 or histone H3 $(n=2)$. Glucose output $(n=4)$ was measured following treatment with c increasing BMP6 concentrations at $24 \mathrm{~h}$, and BMP6 $(300 \mathrm{ng} / \mathrm{mL})$ and cAMP $(0.5 \mathrm{mM})$ at $\mathbf{d} 12$ and $\mathbf{e} 24 \mathrm{~h}$. Results are reported as the mean \pm STDEV. $* p<0.05, * * p<0.01$ vs. control

dose of $5 \mathrm{mg} / \mathrm{kg}$ and exerted its effect mainly via metabolism in the liver [6]. In comparison, BMP6 at doses of 10-60 $\mu \mathrm{g} /$ $\mathrm{kg}$ i.v. reduced glycaemia in diabetic mice with a prolonged effect on maintaining glucose levels. Unlike insulin which acts rapidly in a hormone-like manner, BMP6 has a delayed effect of several hours to several days, respectively, in lowering the plasma glucose. Therefore, it seems likely that BMP6 affects insulin-dependent pathway, ruling out a possibility that it functions as insulin mimetic and/or sensitizer. Similar effect of BMP6 on glucose metabolism was also obtained in our laboratory on other rodent models without obvious alterations in leptin, which implicates that BMP6 affects glucose metabolism independently on possible changes in leptin metabolism (data not shown).

Since liver has a major role in the control of glucose homeostasis, we addressed the question if the acute lowering of glucose was caused by an effect of BMP6 on glucose metabolism in the liver. In experiments on H4IIE 
Fig. 3 Characterization of BMP6 receptor in mediating glucose output. INS1 cells $(n=5)$ transfected with BRELuc were treated for $17 \mathrm{~h}$ with BMP6 $(20 \mathrm{ng} / \mathrm{mL})$ and a Alk3 and $\mathbf{b}$ Alk6 chimera proteins at $0.1,1,10$ and $50 \mu \mathrm{g} / \mathrm{mL}$. Luciferase activity was measured and expressed as relative light units. H4IIE cells $(n=2)$ were treated for $24 \mathrm{~h}$ with c Alk3, d Alk6 and $\mathbf{e}$ ActRIIA Fc at $0.1,1,10$ and $50 \mu \mathrm{g} / \mathrm{mL}$, and glucose was measured in the media. $\mathbf{f}$ H4IIE cells $(n=2)$ were silenced for ActRIIA expression, treated with BMP6 (1, 10 and $100 \mathrm{ng} /$ $\mathrm{mL}$ ) and glucose was measured in the media. Results are reported as the mean \pm STDEV. ${ }^{*} p<0.05,{ }^{* *} p<0.01$ vs. control and no treatment a
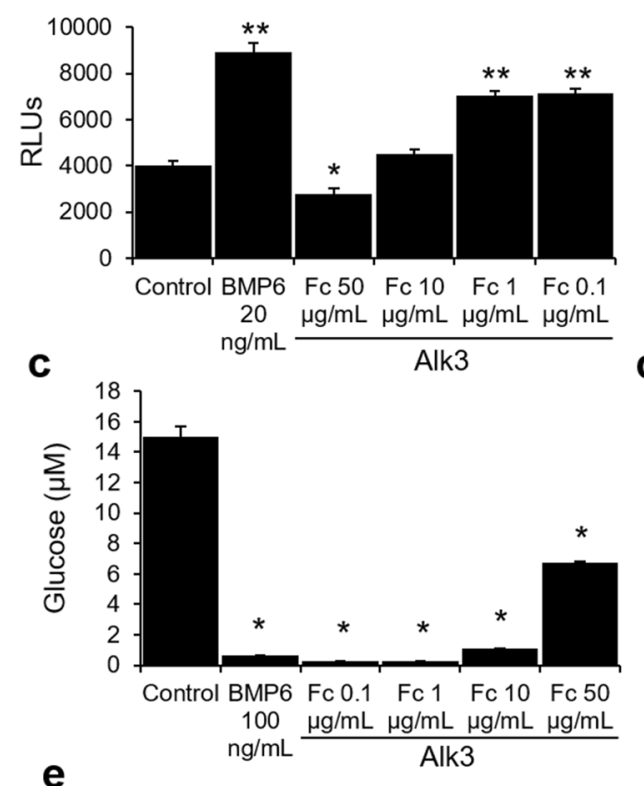

e

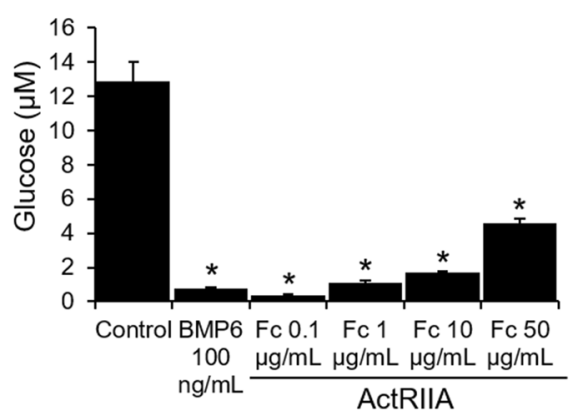

b
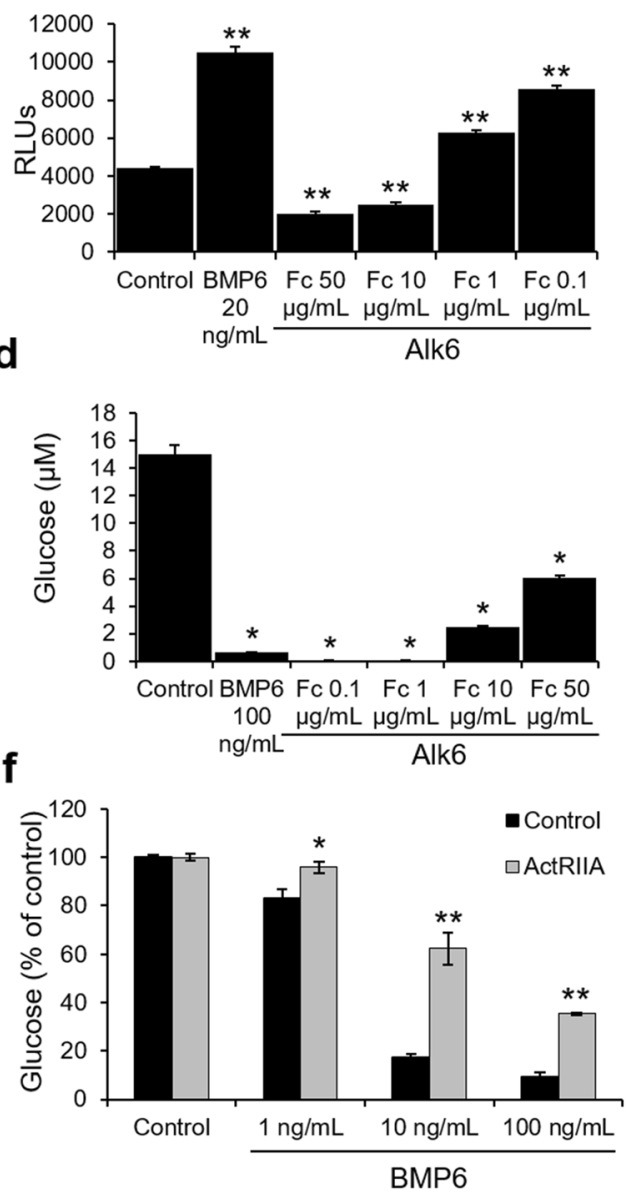

cells, BMP6 treatment significantly reduced PepCK expression and there was a marked decrease in PepCK promoter recruitment following BMP6 administration. PepCK plays a major contributory role in the hyperglycemia characteristic of diabetes, as it catalyzes the reversible decarboxylation of oxaloacetate to yield phosphoenolpyruvate and $\mathrm{CO}_{2}$. Therefore, it was of our interest to further characterize BMP6 and cAMP action in these cells, since cAMP is known to play a major role in the stimulation of PepCK gene transcription. Our results showed that BMP6 directly decreased the glucose production via downregulating PepCK expression at 12 and $24 \mathrm{~h}$ treatment in these cells independently of cAMP. Altogether these results indicate that BMP6, may also act through inhibiting gluconeogenesis in the liver.

BMP receptors and Smad proteins are expressed in $\beta$-cells, whereas BMP ligands are present at low levels, suggesting that the BMP signal transduction is present in the pancreatic islets and that external sources of BMPs are important activators of BMP signaling in the pancreas [5, 7, 14]. BMP6 preferentially binds and signals through Alk2, but can also utilize Alk3 to elicit the Smad signaling $[15,16]$. Interestingly, Alk3 deletion leads to diabetes due to impaired insulin secretion and to a decreased expression of genes involved in insulin gene expression [7]. We found that BMP6 stimulates Smad signaling through binding to Alk3, Alk6 and ActRIIA serine/threonine kinase receptors in H4IIE and $\beta$-cells, initializing signaling events that result in gene transcription regulation.

The presence of BMPs in local microenvironment is important throughout development and homeostasis of almost all organs. BMP6 is required for systemic skeletal development and homeostasis during adult life. We have previously shown that systemic application of BMP6 restores the bone inductive capacity, micro-architecture, and quality of the skeleton in osteoporotic rats [17]. BMP6 exerts its powerful effects on bone volume (BV) by promoting differentiation of MSCs to osteoblasts and decreasing differentiation of hematopoietic stem cells towards the osteoclasts, uncoupling bone remodeling by promoting bone formation and reducing bone resorption. No known therapeutic agent achieves both effects by in vivo systemic administration [18]. Diabetes is associated with changes in bone formation and stem cell differentiation resulting in altered bone mineral density (BMD) and bone structure [19]. In addition, both 
types of diabetes lead to reduced bone strength and increased risk of skeletal fractures. Also, many reports on diabetes show increased osteoclastogenesis and decreased osteoblast formation due to preferential differentiation of mesenchymal stem cells in the marrow towards adipocytes [20, 21]. This could be attributed at least in part by reduced expression of factors that stimulate osteoblasts such as BMPs as was previously reported in rats with T2D [22]. Thus, the role of BMP6 in bone and pancreas development and homeostasis, as well as mediation of long-term effects of bone on glucose metabolism supports its unique properties in systems biology. Furthermore, its resistance to noggin and systemic availability separates BMP6 from other TGF $\beta$ superfamily members [23].

We demonstrated that BMP6 has a delayed effect in lowering plasma glucose in diabetic mice, unlike insulin which acts rapidly in a hormone-like manner. The mechanism is still not fully understood, but at least part of the mechanism seems to involve insulin release and inhibition of gluconeogenesis. Nevertheless, this novel role of BMP6 in the pancreas, liver and the systemic glucose homeostasis suggests a unique function of BMP6 that can be utilized for the treatment of diabetes.

Acknowledgements We thank Djurdjica Car and Mirjana Marija Renic for their technical support in animal experiments.

Funding Research was funded by the Scientific Center of Excellence for Reproductive and Regenerative Medicine (project "Reproductive and regenerative medicine-exploration of new platforms and potentials" GA KK01.1.1.01.0008 funded by the EU through the ERDF).

\section{Compliance with ethical standards}

Conflict of interest The authors declare that there is no conflict of interest.

Ethical approval All experiments were approved by the Institutional Animal Care Review and Ethics Committee, University of Zagreb, School of Medicine.

Informed consent For this type of study, formal consent is not required.

Open Access This article is distributed under the terms of the Creative Commons Attribution 4.0 International License (http://creativeco mmons.org/licenses/by/4.0/), which permits unrestricted use, distribution, and reproduction in any medium, provided you give appropriate credit to the original author(s) and the source, provide a link to the Creative Commons license, and indicate if changes were made.

\section{References}

1. Urist MR (1965) Bone: formation by autoinduction. Science 150:893-899

2. Reddi AH (1998) Role of morphogenetic proteins in skeletal tissue engineering and regeneration. Nat Biotechnol 16:247-252
3. Simic P, Vukicevic S (2004) Bone morphogenetic proteins in development. In: Vukicevic S, Samapth KT (eds) Bone morphogenetic proteins: regeneration of bone and beyond. Birkhauser Verlag, Basel, pp 73-108

4. Sampath KT (2017) The systems biology of bone morphogenetic proteins. In: Vukicevic S, Sampath KT (eds) Bone morphogenetic proteins: systems biology regulators. Springer, Berlin, pp 15-38

5. Grgurevic L, Christensen GL, Schulz TJ, Vukicevic S (2016) Bone morphogenetic proteins in inflammation, glucose homeostasis and adipose tissue energy metabolism. Cytokine Growth Factor Rev 27:105-118

6. Chen C, Grzegorzewski KJ, Barash S et al (2003) An integrated functional genomics screening program reveals a role for BMP-9 in glucose homeostasis. Nat Biotechnol 21:294-301

7. Goulley J, Dahl U, Baeza N et al (2007) BMP4-BMPR1A signaling in beta cells is required for and augments glucose-stimulated insulin secretion. Cell Metab 5:207-219

8. Klein D, Alvarez-Cubela S, Lanzoni G et al (2015) BMP-7 induces adult human pancreatic exocrine-to-endocrine conversion. Diabetes 64:4123-4134

9. Chattopadhyay T, Singh RR, Gupta S et al (2017) Bone morphogenetic protein-7 (BMP-7) augments insulin sensitivity in mice with type II diabetes mellitus by potentiating PI3K/AKT pathway. Biofactors 43:195-209

10. Schreiber I, Dorpholz G, Ott CE et al (2017) BMPs as new insulin sensitizers: enhanced glucose uptake in mature 3T3-L1 adipocytes via PPARgamma and GLUT4 upregulation. Sci Rep 7:17192

11. Dichmann DS, Miller CP, Jensen J et al (2003) Expression and misexpression of members of the FGF and TGFbeta families of growth factors in the developing mouse pancreas. Dev Dyn 226:663-674

12. Martins M, Rosa A, Guedes LC et al (2011) Convergence of miRNA expression profiling, alpha-synuclein interacton and GWAS in Parkinson's disease. PLoS One 6:e25443

13. Livak KJ, Schmittgen TD (2001) Analysis of relative gene expression data using real-time quantitative PCR and the 2(-Delta Delta $\mathrm{C}(\mathrm{T})$ ) Method. Methods 25:402-408

14. Brorson M, Hougaard DM, Nielsen JH et al (2001) Expression of SMAD signal transduction molecules in the pancreas. Histochem Cell Biol 116:263-267

15. Vukicevic S, Grgurevic L (2009) BMP-6 and mesenchymal stem cell differentiation. Cytokine Growth Factor Rev 20:441-448

16. Lavery K, Swain P, Falb D et al (2008) BMP-2/4 and BMP-6/7 differentially utilize cell surface receptors to induce osteoblastic differentiation of human bone marrow-derived mesenchymal stem cells. J Biol Chem 283:20948-20958

17. Simic P, Buljan Culej J, Orlic I et al (2006) Systemically administered bone morphogenetic protein- 6 restores bone in aged ovariectomized rats by increasing bone formation and suppressing bone resorption. J Biol Chem 281:25509-25521

18. Mundy GR (2002) Directions of drug discovery in osteoporosis. Annu Rev Med 53:337-354

19. Sundararaghavan V, Mazur MM, Evans B et al (2017) Diabetes and bone health: latest evidence and clinical implications. Ther Adv Musculoskelet Dis 9:67-74

20. Botolin S, McCabe LR (2007) Bone loss and increased bone adiposity in spontaneous and pharmacologically induced diabetic mice. Endocrinology 148:198-205

21. Botolin S, Faugere MC, Malluche $\mathrm{H}$ et al (2005) Increased bone adiposity and peroxisomal proliferator-activated receptor-gamma2 expression in type I diabetic mice. Endocrinology 146:3622-3631

22. Jiao H, Xiao E, Graves DT (2015) Diabetes and Its effect on bone and fracture healing. Curr Osteoporos Rep 13:327-335

23. Song K, Krause C, Shi S et al (2010) Identification of a key residue mediating bone morphogenetic protein (BMP)- 6 resistance to noggin inhibition allows for engineered BMPs with superior agonist activity. J Biol Chem 285:12169-12180 